\title{
Paradoxical effects of elastase inhibitor guamerin on the tissue repair of two different wound models: sealed cutaneous and exposed tongue wounds
}

\author{
Suk Keun Lee ${ }^{1}$, Sang Shin Lee ${ }^{1}$, \\ In Sun Song ${ }^{1}$, Yeon Sook $\mathrm{Kim}^{1}$, \\ Young Wook Park', Jae Yong Joo ${ }^{2}$, \\ Heung Sik $\mathrm{Um}^{3}$, Jin Woo Kim ${ }^{4}$, \\ Kyeong Yeon Kim ${ }^{5}$, Seung Jin $\mathrm{Choi}^{5}$, \\ Kyung-Hwan Jung ${ }^{5}$ and Soo II Chung ${ }^{1,6}$ \\ ${ }^{1}$ Department of Oral Pathology \\ ${ }^{2}$ Department of Oral and Maxillofacial Surgery \\ ${ }^{3}$ Department of Periodontology \\ ${ }^{4}$ Department of Conservative Dentistry \\ College of Dentistry, Kangnung National University \\ Gangneung, Korea \\ ${ }^{5}$ Mogam Biotechnology Research Institute \\ Yongin, Korea \\ ${ }^{6}$ Corresponding author: Tel, 82-33-640-2228; \\ Fax, 82-33-642-6410; E-mail, rchung@kangnung.ac.kr
}

Accepted 24 May 2004

Abbreviation: DAB, 3,3'-diaminobezidine; PMN, polymorphonuclear leukocyte; $r E I G$, recombinant elastase inhibitor guamerin; SLP1, secretory leukocyte protease inhibitor

\begin{abstract}
Innate elastase inhibitors are known to be putatively involved in the regulation of tissue inflammation by inhibiting polymorphonuclear leukocyte (PMN) derived proteinases. The aim of this study was to evaluate affects of leukocyte elastase suppression and PMN infiltration on wound healing in mouse by administering the recombinant elastase inhibitor guamerin (rEIG) in two different wound models; 1) impaired pin-punctured dorsal mucosa of anterior tongue wound, 60 mice, treated with saline containing rEIG that were fed ad libitum and 2) stable linear excisional cutaneous wound, 40 mice, covered with fibrin sealant containing rEIG. The progress of healing was analyzed by histological methods. The tongue wounds treated with rEIG became edematous around the pin-punctured tongue wound, and influx of inflammatory cells and $P M N$ into the underlying stromal tissue
\end{abstract}

were seen rapidly after wounding and peaked between 2-4 days. Whereas the control mice showed almost no wheal formation in the pin-punctured wound, a far lesser levels of PMN infiltration, and almost complete wound closure in 4 days. In the other model, the liner excisional cutaneous wound treated with fibrin sealant containing rEIG showed early wound constriction, lesser degree of inflammatory cells influx, and complete reepithelialization in 4-5 days, whereas the wound of control mice with the fibrin sealant alone showed contrary delayed reepithelialization, greater degree of inflammatory cell infiltration, and consequencial formation of greater granulation tissue at wound site. Taken together, these data suggest paradoxical effects of rEIG on the wound healing where in the wound exposed to infiltrating milieu of $\mathrm{mi}$ croorganisms in the oral cavity, the rEIG aggravates the wound healing by interfering with other innate defensive factors and extended greater flux of PMNs to inflamed wound site, while in the wound enclosed by fibrin, the rEIG accelerated wound healing by inhibiting the inflammation-generated proteases and the acute inflammatory reaction.

Keywords: leukocyte elastase; mice; recombinant proteins; serine proteinase inhibitors; skin; tongue; wound healing

\section{Introduction}

Neutrophil elastase is a protease that is involved in the tissue destruction and inflammation that characterize numerous diseases, including hereditary emphysema, chronic obstructive pulmonary disease, cystic fibrosis, adult respiratory distress syndrome, ischemic-reperfusion injury, rheumatoid arthritis, and periodontitis (Drugarin et al., 1998; Tremblay et al., 2003). A significant increase of the PMN-elastase and proinflammatory cytokines level was found in crevicular gingival fluid of patients with gingivitis and periodontitis. The intensity of the inflammatory response in these diseases is strongly correlated to the activation of the neutrophil granulocytes which release 
these biological active molecules (Drugarin et al., 1998; Kang et al., 2000). Crevicular gingival fluid elastase levels are significantly higher in sites demonstrating progressive periodontal detachment and bone loss (Palcanis et al., 1992; Eley and Cox, 1996). Secretory leukocyte protease inhibitor (SLPI) is a serine protease inhibitor with anti-microbial properties found in mucosal fluids. It is expressed during cutaneous wound healing. In the SLPI-null mice, the impaired cutaneous wound healing with increased inflammation and elastase activity was observed suggesting that leukocyte protease inhibitor may play a pivotal role for optimal wound healing and the altered inflammatory profile involves enhanced activation of local TGF- $\beta$ in SLPI-null mice (Ashcroft et al., 2000; Shin et al., 2003).

Different types of elastase inhibitors have been characterized from human skin (Lammers et al., 1986), parotid secretions, and bronchial mucus (Hochstrasser et al., 1981), as well as from other sources such as soybean (Odani and Ikenaka, 1978), turkey ovomucoid and leech (Seemuller et al., 1980) and suggested that the innate elastase inhibitors may play an important role for the protection of organs and tissues (Ashcroft et al., 2000; O'Blenes et al., 2000; Tonai et al., 2001; Ueno et al., 2001; Waugh et al., 2001). Furthermore, the leukocyte elastase inhibitors were considered as potential therapeutic agents for preventing number of chronic inflammatory diseases. And to that end, there have been greater effort to isolate and characterize various protease inhibitors from variety of natural resources such as animals and plants (Rees et al., 1997; Cantin and Woods, 1999; Wright et al., 1999).

The new leukocyte elastase inhibitor, guamerin, is a low molecular weight cysteine-rich polypeptide isolated from Korean native leech Hirudo nipponia. Guamerin is stable at a wide range of $\mathrm{pH}$ from 1 to 11 , also heat-stable up to $90^{\circ} \mathrm{C}$, and demonstrated to inhibit the human neutrophil elastase quite efficiently (Jung et al., 1995; Kim et al., 1996; Song et al., 1999). In this study, the effect of a recombinant elastase inhibitor guamerin ( $r E I G)$ was analyzed in the animal wound models where degree of inflammation and exposure to infectious agents were significantly different. One animal model of septic open wound was prepared by pin-puncture on the dorsal tongue mucosa, and exposed to salivary milieu containing all infectious agents of oral cavity and administered saline solution containing rEIG. The other model of aseptic semi-enclosed wound was prepared by a linear excision on the back skin sealed immediately by fibrin clot containing rEIG. Paradoxical effect of rEIG on the healing of two different model wounds appeared a hindrance in the septic and an aid in aseptic conditions suggesting a possible multi-role(s) of elastase on the progression of inflammation at wound sites.

\section{Materials and Methods}

\section{rEIG}

rEIG, produced from Pichia pastoris as described previously (Kim K.Y. et al., 2000; Lim H. K et al., 2000), was tested free of any endotoxin contamination.

\section{Animal experiment}

Total 100 four weeks old female mice (BALB/c) were used for the effect of $r E I G$ on the open wound and semi-enclosed wound separately. For the open wounds 60 mice were used for the puncture of the dorsal tongue mucosa by a pin, $0.6 \mathrm{~mm}$ in diameter. Among them thirty mice were given the sterile water containing $\mathrm{rEIG}(10 \mathrm{ng} / \mathrm{ml})$ ad libitum for $5 \mathrm{~d}$, and the remaining thirty mice were given the normal water for $5 \mathrm{~d}$ as a control group. Forty mice were used for the preparation of the semi-enclosed wound covered by fibrin sealant (Green Cross Corp., Korea) in the linear excisional wound on the back skin. Among them 20 mice were used for the incision wound covered with the fibrin sealant containing $\mathrm{rEIG}(100 \mathrm{ng} / \mathrm{ml})$, and the remaining twenty mice were used for the excisional wound covered with fibrin sealant only as a control group. All mice were housed in clean cages for $5 \mathrm{~d}$.

\section{Histological observation}

Specimens obtained from the tongue and back skin of mice were fixed in $10 \%$ buffered formalin and embedded in paraffin. Serial sections were made around the wound area in $4 \mu \mathrm{m}$ thickness. The microsections were stained with hematoxylin and eosin and observed by light microscope (Olympus, Japan).

\section{Antibody production}

For obtaining the anti-sera against rEIG, subcutaneous injections of rEIG $(500 \mu \mathrm{g} / \mathrm{head})$ into rabbit were performed, in which complete or incomplete Freud's adjuvant (GIBCO Laboratories) was added for the first or the second injection, respectively. At the second week after the first injection, the second injection (boosting) was carried out. At the fourth weeks after the first injection, the rabbit was bled to obtain the antibody against $\mathrm{rEIG}$. Isolation of $\mathrm{IgG}$ from the serum was performed using a protein A-agarose column (Affi-Gel MAPS II, Bio-Rad), and followed by antigen affinity gel purification by AminoLink coupling gel (Pierce, Woburn, MA) immobilized by rEIG. The purified antibody was preserved in refrigerator and applied for the immunological techniques as soon as 
possible.

\section{Immunohistochemical study}

Paraffin sections were treated with mono-specific antibodies of rEIG by indirect immunohistochemical method using labeled streptavidin-biotin (Dako, Denmark) staining technique. 3-3'Diaminobenzidine (DAB) was precipitated by peroxidase reaction in dark brown color, and the result was observed without counter staining. Immunohistochemical methods, histological details are basically same as the previous study (Lee et al., 1995). For the negative control the microsections were applied with pre-immune rabbit serum and simultaneously processed with the above immunostainings.

\section{Western blot analysis}

In order to confirm the specific reaction of guamerin antibody we performed western blot using the rEIG as a positive control and protein extracts from mouse liver as a negative control. An aliquot was mixed with an equal volume of protein lysis buffer $(0.3 \%$ SDS, $0.05 \mathrm{M}$ Tris- $\mathrm{HCl}, \mathrm{pH} 8.0,1 \% \beta$-mercaptoethanol) and boiled for $5 \mathrm{~min}$ in the presence of $100 \mathrm{mM}$ DDT. Samples $(30 \mu \mathrm{g})$ were applied to a polyacrylamide gel. SDS-PAGE analysis was carried out in a $8 \times 7.5$ inch gel apparatus (Novex, San Diego, CA), with use of the discontinous Tris/glycine buffer system (Laemmli, 1970, 10\% cross-linked gel). The fractionated proteins on polyacrylamide gel were transferred elec- trophoretically onto a nitrocellulose strip. The strip was blocked with skim milk in Tris- $\mathrm{HCl}$ buffer and washed with $0.05 \%$ Tween 20 and incubated overnight with purified anti-guamerin antibody in $1 \%$ gelatin solution at $4^{\circ} \mathrm{C}$. The strip was treated with horseradish peroxidase-conjugated Protein A (BioRad, $1: 200$ dil). The washed strip was developed for 2 to 15 min with 4-chloro-1-napthol, hydrogen peroxide reagent (Lee et al., 1995).

\section{Results}

\section{Pin-punctured tongue wound}

The pin-punctured wound on the dorsal tongue mucosa produced a focal laceration in the epithelium and underlying fibromuscular tissue. The gross and microscopic observations on the healing process of the pin-punctured wound showed a somewhat delayed wound closure due to the versatile movement of tongue during deglutition and mastication (Table 1, Figure 1). In the 1st day of the experiment the control mice showed focal ulceration covered with hematoma but no excessive wheal formation around the wound area (Figure 1-a1). In contrast, the rEIG treated mice showed a deep ulceration covered with pseudonecrotic membrane at the pin-punctured wound and the wound area was quite edematous (Figure 1-a2). On 2nd day of experiment the pin-punctured wounds of control mice were constricted to an almost closed state showing a residual amount of hematoma and

Table 1. Effect of rEIG in the pin-punctured wound of dorsal tongue mucosa of mouse.

\begin{tabular}{|c|c|c|c|c|c|c|c|c|}
\hline \multirow{2}{*}{\multicolumn{2}{|c|}{$\begin{array}{l}\text { Experimental } \\
\text { days and group }\end{array}$}} & \multirow{2}{*}{$\begin{array}{c}\text { Total } \\
\text { No. }\end{array}$} & \multicolumn{3}{|c|}{ Gross findings } & \multicolumn{3}{|c|}{ Microscopic findings } \\
\hline & & & Bleeding & Ulceration & Recovered & Severe Inf. & Abscess & Epithelialization \\
\hline 1 & control & 6 & $2 / 6$ & $6 / 6$ & 0 & $4 / 6$ & $2 / 6$ & 0 \\
\hline 1 & rEIG & 6 & $3 / 6$ & $6 / 6$ & 0 & $4 / 6$ & $3 / 6$ & 0 \\
\hline 2 & control & 6 & $1 / 6$ & $2 / 6$ & $1 / 6$ & $4 / 6$ & $2 / 6$ & 0 \\
\hline 2 & rEIG & 6 & $3 / 6$ & $5 / 6$ & 0 & $4 / 6$ & $5 / 6$ & 0 \\
\hline 3 & control & 6 & 0 & $3 / 6$ & $3 / 6$ & $2 / 6$ & $1 / 6$ & $3 / 6$ \\
\hline 3 & rEIG & 6 & $1 / 6$ & $5 / 6$ & 0 & $3 / 6$ & $4 / 6$ & 0 \\
\hline 4 & control & 6 & 0 & 0 & $4 / 6$ & $1 / 6$ & 0 & $5 / 6$ \\
\hline 4 & rEIG & 6 & 1 & $3 / 6$ & $1 / 6$ & $2 / 6$ & $3 / 6$ & $1 / 6$ \\
\hline 5 & control & 6 & 0 & 0 & $6 / 6$ & 0 & 0 & $6 / 6$ \\
\hline 5 & rEIG & 6 & 0 & $2 / 6$ & $4 / 6$ & $2 / 6$ & $2 / 6$ & $4 / 6$ \\
\hline
\end{tabular}

Total $\quad 60$

Gross findings: bleeding; continuous hemorrhage was seen, ulceration; sharp ulcer margin was seen, recovered; ulcer area was covered with epithelium. Microscopic findings: severe inflammatory (Inf.) cell infiltration; a lot of inflammatory cells were observed in the underlying connective tissue, abscess; collection of inflammatory cells, epithelialization; new epithelial growth was completed. 

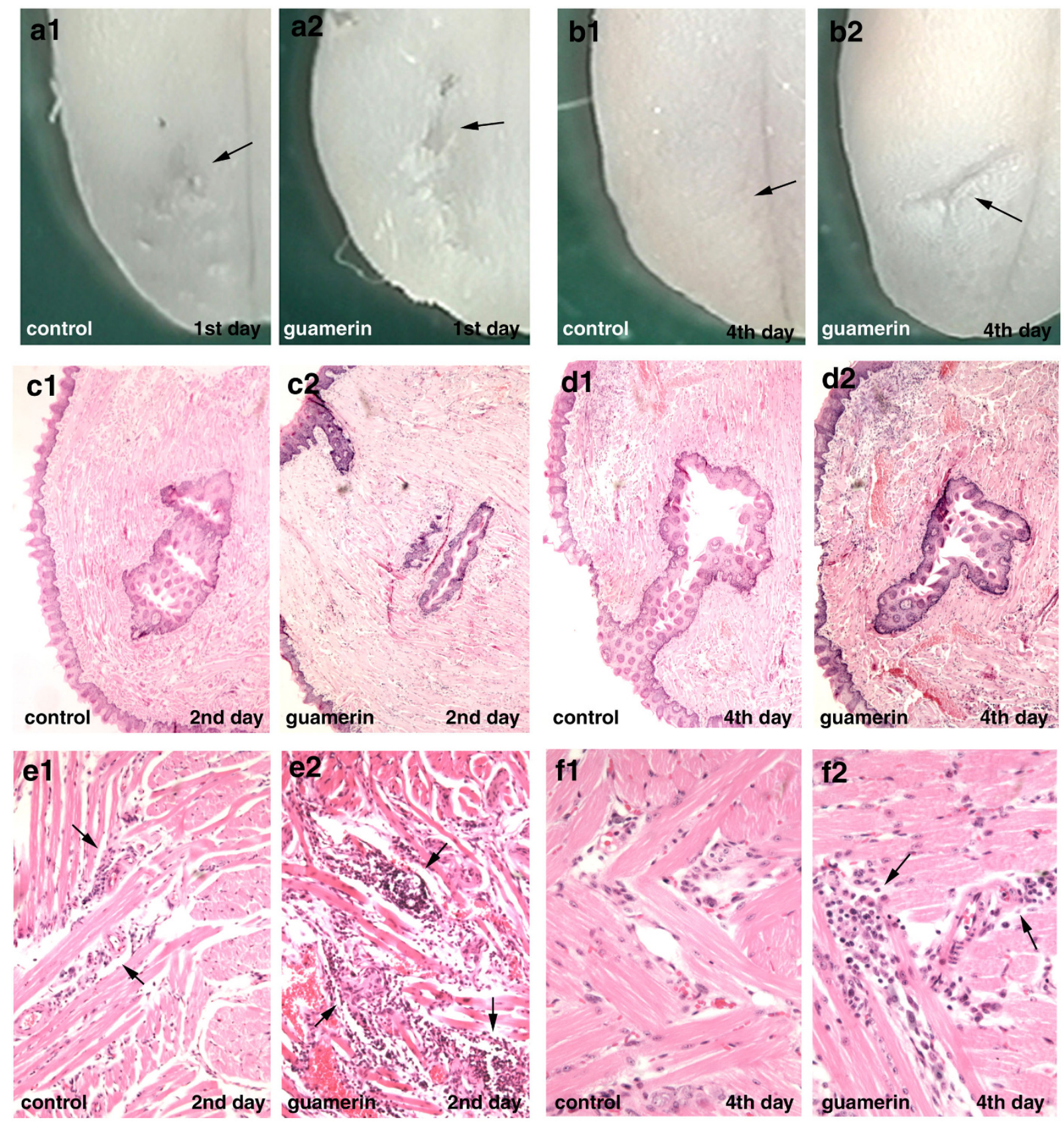

Figure 1. Pin punctured wound healing on the dorsal mucosa of mouse tongue. a: on the 1st day, a1: control group fed with normal water, a2: experiment group fed with $\mathrm{rEIG}$ solution $(10 \mathrm{ng} / \mathrm{ml})$. Histological findings of pin-punctured wound. $c 1, \mathrm{~d} 1, \mathrm{e} 1, \mathrm{f1}$ : control group, $c 1, \mathrm{e} 1$ : on the 2nd day, c1: cross section of punctured tunnel, e1: mild infiltration of inflammatory cells (arrows, $x 400$ ), d1, f1: on the 4th day, d1: cross section of punctured tunnel, f1: almost no inflammatory cell in the muscular layer (×400). c2, d2, e2, f2: experimental group, c2, e2: on the 2nd day, c2: cross section of punctured tunnel, e2: marked infiltration of inflammatory cells (arrows, $\times 400$ ), d2, f2: on the 4th day, d2: cross section of punctured tunnel, f2: persisted inflammatory cell infiltration (arrows, $\times 400$ ).

the epithelium-lined tunnel structure in the underlying muscular tissue of the wound (Figure 1-c1) with diffuse and slight infiltration of inflammatory cells (Figure 1-e1), while the pin-punctured wounds of the rEIG treated mice became deeply ulcerated open wound that are covered with pseudo-necrotic mem- brane and the epithelium-lined tunnel structure was much dilated (Figure 1-c2) with increased infiltration of inflammatory cells in the underlying muscular tissue of the wound (Figure 1-e2). On the 3rd day, the control mice showed re-epithelialization of dorsal tongue mucosa, while the rEIG-treated mice showed 

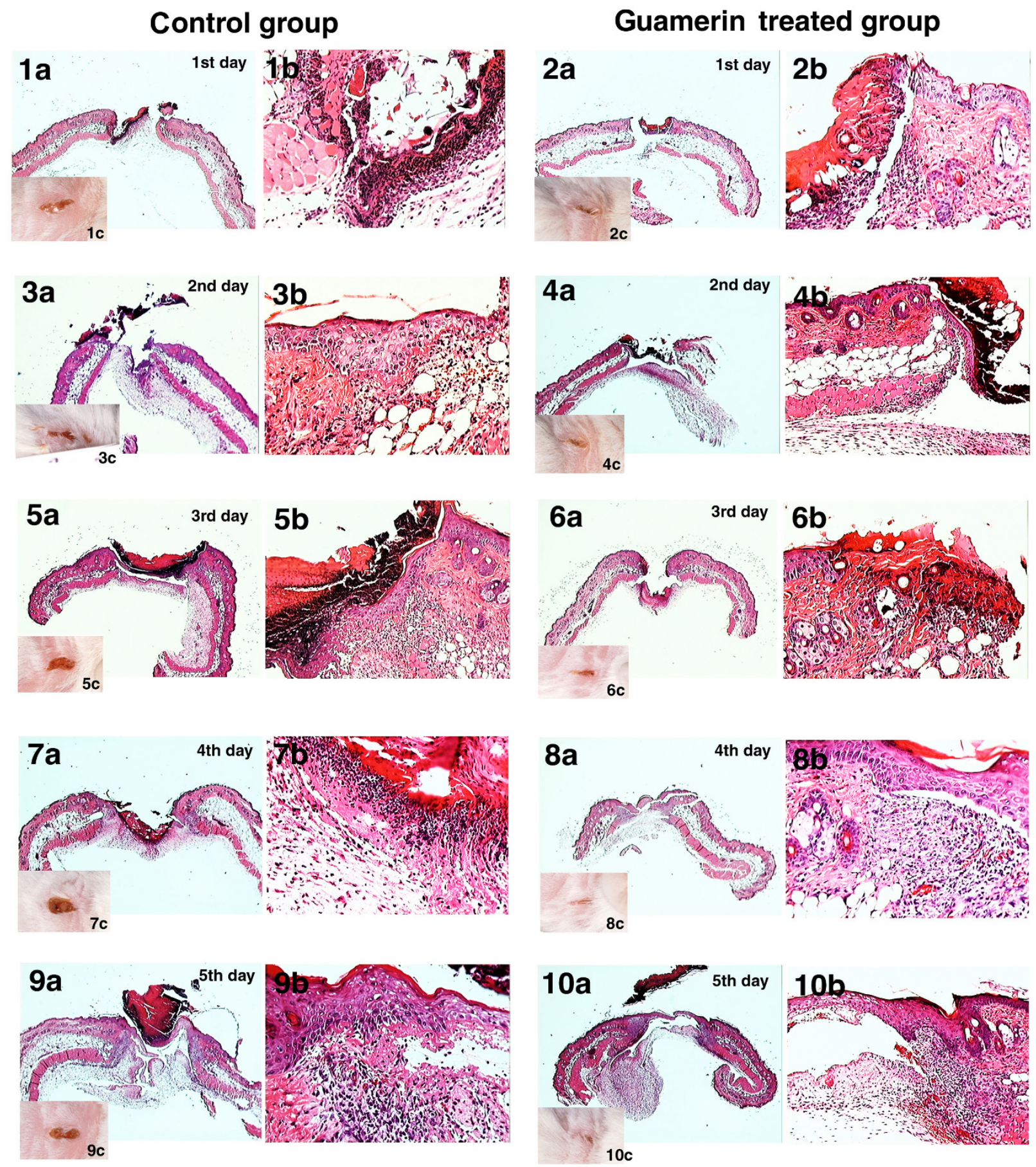

Figure 2. Excisional cutaneous wound healing on the back skin of mouse. 1c-10c: gross observation. 1a-10a: low magnification ( $\times 6)$, 1b-10b: high magnification of microscopic observation with hematoxylin and eosin stain $(\times 200)$. 1, 3, 5, 7, 9: control group using fibrin sealant only, $2,4,6,8$, 10: experimental group using fibrin sealant containing $\mathrm{rEIG}$.

conspicuous ulceration with pseudonecrotic membrane. The underlying muscular tissue was heavily infiltrated with inflammatory cells, producing focal abscess till the 3rd day. On the 4th day, the control mice showed complete healing of the pin punctured wound on the dorsal tongue mucosa without any residual inflammatory cell in the underlying muscular tissue (Figure 1-b1, d1, f1), while the rEIG-treated mice showed incomplete healing of the pin-punctured wound (Figure 1-b2), still showing deep ulceration and 
a dilated tunnel structure lined with epithelium (Figure 1-d2, f2). A significant level of inflammatory cell infiltration was found in the underlying muscular tissue of mouse tongue, and this inflammatory reaction was observed until the 5th day. We have limited the experiments for five days in this wound model due to host antibody formation to rEIG after 6th day whereas in the coutaneous excisional wound model, a single dose level $(10 \mathrm{ng} / \mathrm{ml})$ in the gel sealant did not induce any immune reaction to rEIG (data not shown). In gross and microscopic observations the rEIG-treated group of the pin-punctured tongue wound experiment clearly showed the trend of delayed wound healing, displaying persisted ulceration and abscess formation compared to the control group (Table 1).

\section{Excisional cutaneous wound on the back skin}

The excisional cutaneous wound on the back of mouse skin was immediately enclosed aseptically with fibrin sealant to provide a protective barrier from the exposure to microorganisms and limit from other excessive physiological and physical damage. On the 1 st day, control mice wounds showed sharp ulcer filled with hematoma and infiltration of heavy inflammatory cells (Figure 2-1a, 1b, 1c), while those of rEIGtreated mice showed relatively constricted ulcer with fewer inflammatory cell infiltration (Figure 2-2a, 2b, $2 c)$. On the 2 nd day, the wounds of control mice were filled with hematoma clot but not constricted enough to close the wound (Figure 2-3c) displaying necrotic ulcer lesion with the infiltration of numerous inflammatory cells into deep connective tissue (Figure 2-3a, 3b), while the wounds of rEIG-treated mice were well constricted to a slight gap wound filled with a few patches of hematoma clot (Figure 2-4a, 4c). The ulceration was greatly reduced retaining a few inflammatory cells (Figure 2-4b). On the 3rd day, the wound ulceration of control mice persistent with thick necrotic membrane accompanying heavy infiltration of inflammatory cells (Figure 2-5a, 5b, 5c), while those of rEIG-treated mice were almost retracted to a small linear excisional mark (Figure 2-6a, 6c), showing the growth of granulation tissue in the underlying connective tissue (Figure 2-6b). On the 4th day, the wounds of control mice were partly infected and presented ulcerated lesion with an evidence of exudate formation (Figure 2-7a, 7c) heavily infiltrated with acute inflammatory cells (Figure 2-7b), while those of rEIG-treated mice were almost retracted and reduced in size (Figure 2-8a, 8c) to prewound state showing re-epithelialization with granulation tissue in the underlying connective tissue (Figure 2-8b). On the 5th day of experiment the wounds of control mice were still deeply ulcerated with inflammatory exudate and superficial necrosis (Figure 2-9a, 9c), and there still retained-heavy inflammatory reaction along with scarlike fibrosis in the underlying connective tissue (Figure 2-9b). Whereas those of rEIG-treated mice were almost healed and well reepithelialized with well organized connective tissue (Figure 2-10a, 10b, 10c).

Table 2. Effect of $\mathrm{rEIG}$ in the incisional wound on the back skin of mouse, which was immediately covered with fibrin sealant.

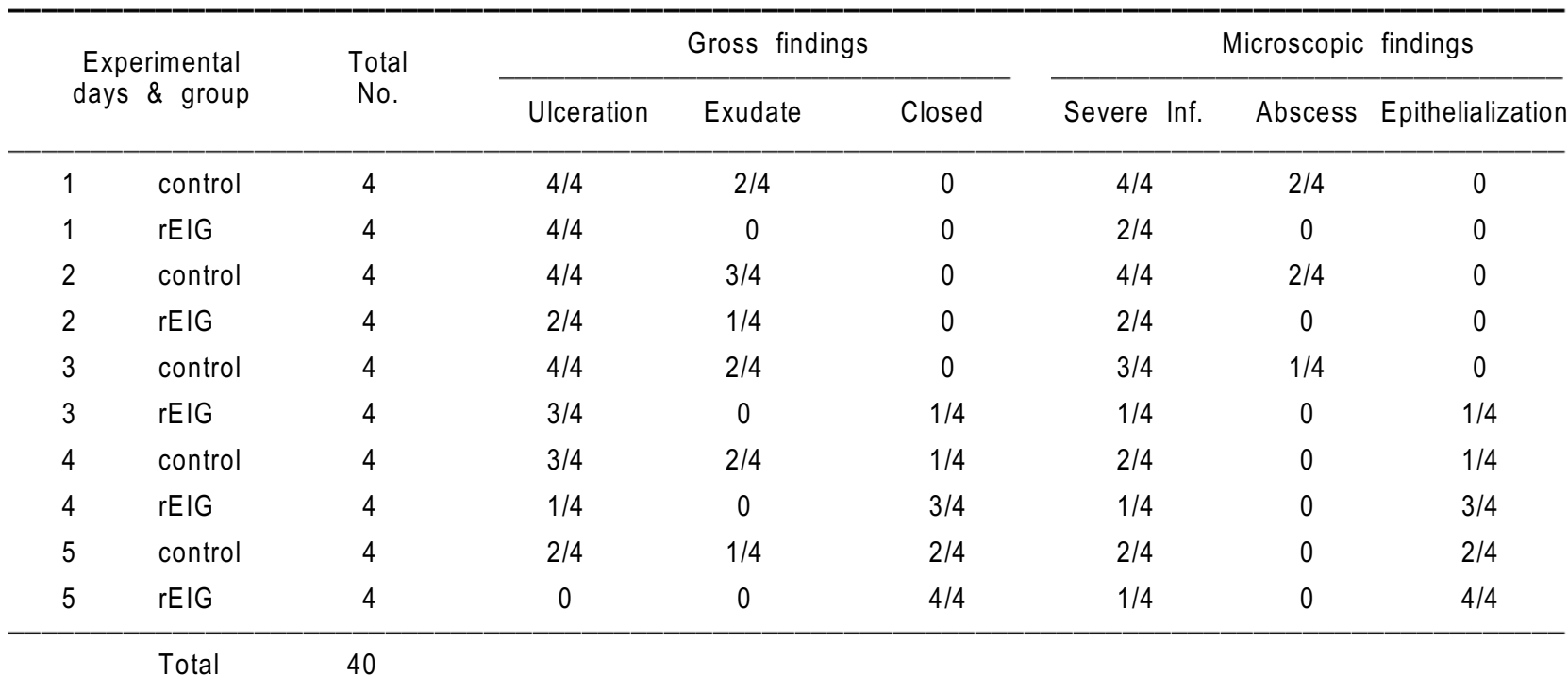

Gross findings: ulceration; the wound was clearly opened, exudates; the ulcer was filled with transparent fluid, closed; the wound was almost constricted. Microscopic findings: severe inflammatory (Inf.) cell infiltration; a lot of inflammatory cells were observed in the underlying connective tissue, abscess; collection of inflammatory cells, epithelialization; new epithelial growth was completed. 


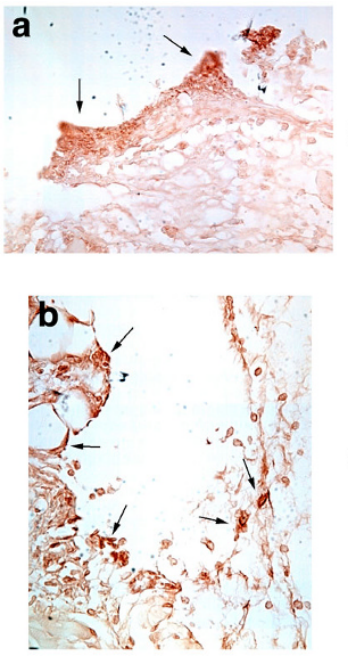

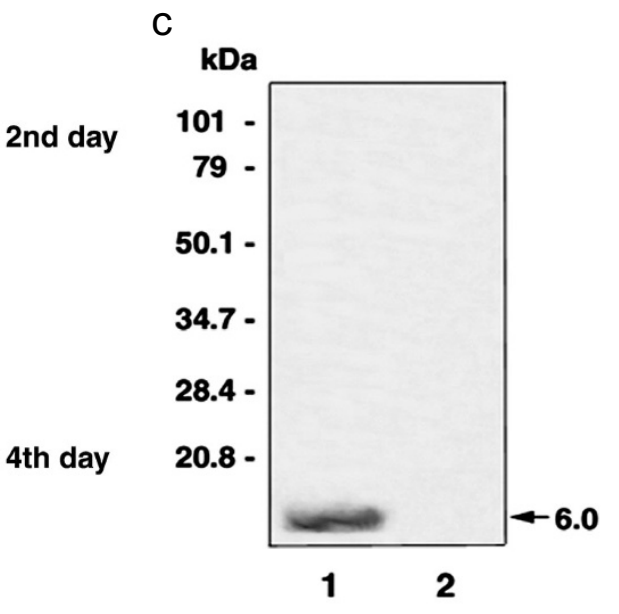

Figure 3. Immunohistochemical staining using $r E I G$ antibody, no counter staining. (a) 2nd day of rEIG treatment, appeared a layer of $\mathrm{rEIG}$ positive reaction on the base of the excisional wound (arrows, x400). (b) 4 th day of $\mathrm{rEIG}$ treatment, wound healing was progresses, noted the strong positive reaction of guamerin in macrophages (arrows, x400). Western blot analysis to test the specific reaction of guamerin antibody. (c) lane 1, rEIG was positive at $6.0 \mathrm{kDa}$ band (arrow); lane 2, protein extract from mouse liver was negative.
In gross and microscopic observations the rEIGtreated group of the excisional cutaneous wound experiment showed the advanced wound healing, resulted in the early constriction and reepithelialization of the wound in five days (Table 2).

\section{The metabolic state of administered rEIG in wound sites}

The purified $\mathrm{rEIG}$ antibody specificially recognized the rEIG as a unique band, migrated about $6 \mathrm{kDa}$ (Figure 3-c, lane 1), while it was negative for the protein extract from mouse liver (Figure 3-c, lane 2) indicating that mice innate elastase inhibitors did not crossreacted with rabbit antibody to rEIG from leech. In an effort to estimate the metabolic fate of the administered $\mathrm{rEIG}$ in mice, the wounds tissues were analyzed with immunohistochemistry with antibody to rEIG. The result showed that the rEIG was abundantly remained on the ulcer base of excisional wound in the 2nd day of experiment (Figure 3-a), and it was gradually degraded and phagocytosed by the infiltrated macrophages until the 4th day of experiment (Figure 3-b). However, we observed that the rEIG was persistently remained in the granulomatous tissue of wound until the 5th day of experiment. Such results suggest that the level of $\mathrm{rEIG}$ administered with fibrin sealant was able to control leukocyte proteases and also protected the fibrin covered matrix from the surrounding regenerating tissues.

\section{Discussion}

Guamerin, a new leukocyte elastase inhibitor, has a cysteine-rich polypeptide of 57 amino acid residues, putatively $6.1 \mathrm{kD}$ of molecular weight and is stable at a wide range of $\mathrm{pH}$ from 1 to 11 and heat-stable up to $90^{\circ} \mathrm{C}$ (Jung et al., 1995). Tests for the acute toxicity and antigenicity of rEIG was performed separately and revealed that it was safe and did not induce active systemic anaphylaxis and passive cutaneous anaphylaxis (Kim et al., 2000). The 50\% lethal dose $\left(L D_{50}\right)$ of $r E I G$ for ICR mice was more than $1,000 \mathrm{mg} / \mathrm{kg}$ when intravenously injected (Song et al., 1999; Kim et al., 2000). And rEIG (10 $\mu \mathrm{g} / \mathrm{kg})$ injection in combination with urinary trypsin inhibitor $(7,500$ $\mathrm{IU} / \mathrm{kg}$ ) had a beneficial effect on cerulein-induced acute pancreatitis rat model by reducing the serum level of amylase and lipase (Shin et al., 2000).

In human gingivitis, the released leukocyte elastase from influxed inflammatory cells has been implicated as being the responsible factor for detachment of periodontal tissues and tooth dentin (Palcanis KG et al., 1992). In this study we explored the wound healing effect of the elastase inhibitor treatment on the model wounds in mice relating to human periodontitis, i.e., a pin-punctured wound on the dorsal tongue mucosa relating to open wounds in oral mucosa with greater opportunity for additional physical and microbial re-infection. For the open pin-pucture wounds of mobile tongue, rEIG was given by ad libitum via feeding water in the concentration of 10 $\mathrm{ng} / \mathrm{ml}$, which is 10 times higher than the expected therapeutic dose of rEIG used for pancreatitis experiments (Song et al., 1999; Shin et al., 2000), because the rEIG solution would be more diluted with saliva and food and even rapidly swallowed. The results were puzzling and paradoxical. A reasonable explanation may be that although the precise pharmacological role of guamerin is not clearly understood, the anti-inflammatory effect of $\mathrm{rEIG}$, as a potent elastase inhibitor, was ascribed partially to the inhibition of leukocyte migration and that aggravation 
of the wounds by persistent bacterial infection in rEIG-treated mice is probably due to the absence of primary phagocytosis by leukocytes at initial stages. However, whatever the explanation may be, it is clear that leukocyte elastase was found to play anti-inflammatory effect in the mucosa epithelium of the oral cavity.

It was also reported that the elafin-overexpressing mice showed the suppressed smooth muscle proliferation and inflammatory cell infiltration by an experiment using wire-induced endothelial denudation of the carotid artery where there are no foreign microbial invasion exist (Zaidi et al., 2000). This report presented very complex inflammation associated host response to wound healing, however, it did not include "pro and con" of maturation processes of wounds in the elafin over-expressing mice model. We were seriously contemplated carrying out exactly the real experiments not using any antibiotics, because oral environment is far more complex than simple degree of bacterial intervention. First, certain measure of animal host bacteria responsible for continuous infection in each should be identified for the reason that there are grossly over 500 known bacterium exist (in humans), and depend on antibiotic type selection, it could shift the balance of bacteria population to create more infection than curtailing it. Second, even with the use of broad spectrum antibiotics, again left with shifting the balance of microbes and does not guarantee the complete removal of invading bacteria. In addition, saliva is enriched with various innate antimicrobial peptides that are critically dependent on the proteolytic processing. Lastly, use of antibiotic does not provide clear evidence for added and probable enhanced infection of bacteria in the elastase inhibitor, guamerin-treated mice oral cavity. Even if we were successful to knock off certain type(s) of bacteria by using batteries of antibiotics, the control animals could have different response due to different wound healing response. Therefore, in the present study we selected the different wound healing models, an exposed pin-punctured tongue wound and a sealed excisional cutaneous wound, and observed the paradoxical effect of $\mathrm{rEIG}$ on the tissue repair processes in the absence of antibiotic intervention.

An excisional cutaneous wound was made on the back skin of mice in order to avoid any further physical injury. The cutaneous wound was not stitched and remained open but covered with excessive natural fibrin sealant that is further cross-linked to host tissue matrix as protective barrier for external microbial infiltration as well as accelerating the wound healing by its components of different growth factors (Gaboriau et al., 1999; Kjaergard et al., 1999; Bolliger-Stucki et al., 2000). In this model, a potent antiinflammatory effect of guamerin was observed in the semi-enclosed cutaneous wound, remained almost in an aseptic condition, until the 5 th day of experiment. The fact that the rEIG treatment accelerated the healing of skin wound could be due to a number of mechanisms; 1) rEIG plays an inhibitory role for the early inflammatory reaction, i.e., chemotaxis of leukocytes, 2) the direct inhibitory role of elastase, known to be responsible for tissue erosion and also lysis of the formed fibrin clot at tissue injury sites. Thus, inhibiting such excessively generated elastase should preserve and extend the stability of provisional matrix fibrin at wound site and consequential enhancement of tissue repair processes. An effect observed in the rEIG treatment in the experimentally induced mouse pancreatitis (Song et al., 1999; Shin et al., 2000) certainly may support both of these mechanisms.

\section{Acknowledgement}

We are grateful to the histological assist of $\mathrm{Ji}$ Yong Song. This work was supported by grants R112002-001-03003-0 and R01-2003-000-10891-0 from the Korean Science and Engineering Foundation.

\section{References}

Ashcroft GS, Lei K, Jin W, Longenecker G, Kulkarni $A B$, Greenwell-Wild T, Hale-Donze H, McGrady G, Song XY, Wahl SM. Secretory leukocyte protease inhibitor mediates non-redundant functions necessary for normal wound healing. Nat Med 2000;6:1147-53

Bolliger-Stucki B, Baillod P, Mader W, Furlan M. Biochemical properties of the fibrinogen component of a fibrin glue before and after severe dry heat treatment [In Process Citation]. J Biomed Mater Res 2000;53:577-83

Cantin AM, Woods DE. Aerosolized prolastin suppresses bacterial proliferation in a model of chronic Pseudomonas aeruginosa lung infection. Am J Respir Crit Care Med 1999; 160:1130-5

Drugarin D, Onisei D, Koreck A, Negru S, Drugarin M. Proinflammatory cytokines production and PMN-elastase release from activated PMN cells in the periodontal disease. Roum Arch Microbiol Immunol 1998 57:295-307

Eley BM, Cox SW. A 2-year longitudinal study of elastase in human gingival crevicular fluid and periodontal attachment loss. J Clin Periodontol 1996 23:681-92

Gaboriau HP, Belafsky PC, Pahlavan N, Amedee RG. Closure of mucosal defects over exposed mandibular plates using fibrin glue. Arch Facial Plast Surg 1999;1:191-4

Hochstrasser K, Albrecht GJ, Schonberger OL, Rasche B, Lempart K. An elastase-specific inhibitor from human bronchial mucus. Isolation and characterization. Hoppe Seylers Z Physiol Chem 1981;362:1369-75

Jung HI, Kim SI, Ha KS, Joe CO, Kang KW. Isolation and characterization of guamerin, a new human leukocyte elastase inhibitor from Hirudo nipponia. J Biol Chem 1995; 


\section{$270: 13879-84$}

Kang K, Bae SJ, Kim WM, Lee D-H, Cho U, Lee MH, Lee M-S, Nam S, Kuettner KE, Schwartz DE. Molecular chracteristics of the inhibition of human neutrophil elastase by nonsteroidal antiinflammatory drugs. Exp Mol Med 2000;32: $146-54$

Kim DR, Hong SJ, Ha KS, Joe CO, Kang KW. A cysteine-rich serine protease inhibitor (Guamerin II) from the non-blood sucking leech Whitmania edentula: biochemical characterization and amino acid sequence analysis. J Enzyme Inhib 1996;10:81-91

Kim KY, Lim HK, Lee KJ, Park DH, Kang KW, Chung SI, Jung $\mathrm{KH}$. Production and characterization of recombinant guamerin, an elastase-specific inhibitor, in the methylotrophic yeast Pichia pastoris. Protein Expr Purif. 2000;20:1-9

Kjaergard HK, Velada JL, Pulawska T, Ellensen VS, Larsen SS, Hollingsbee DA. Development of a model for measurement of adhesion strength of fibrin sealant to human tissue. Eur Surg Res 1999;31:491-6

Lammers AM, van de Kerkhof PC, Schalwijk J, Mier PD. Elastase, a marker for neutrophils in skin infiltrates. $\mathrm{Br} \mathrm{J}$ Dermatol 1986;115:181-6

Lee SK, Chi JG, Jeon YJ, Park SC, Mori M, Chung SI. Expression of transglutaminase $C$ during the prenatal development of human submandibular glands. J Dent Res 1995; $74: 1812-6$

O'Blenes SB, Zaidi SH, Cheah AY, Mclntyre B, Kaneda Y, Rabinovitch M. Gene transfer of the serine elastase inhibitor elafin protects against vein graft degeneration. Circulation 2000;102:III289-95

Odani S, Ikenaka T. Studies on soybean trypsin inhibitors. IV. Change of the inhibitory activity of Bowman-Birk inhibitor upon replacements of the alpha-chymotrypsin reactive site serine residue by other amino acids. J Biochem (Tokyo) 1978;84:1-9

Palcanis KG, Larjava IK, Wells BR, Suggs KA, Landis JR, Chadwick DE, Jeffcoat MK. Elastase as an indicator of periodontal disease progression. J Periodontol. 1992;63:23742

Rees DD, Brain JD, Wohl ME, Humes JL, Mumford RA. Inhibition of neutrophil elastase in CF sputum by L-658,758. J Pharmacol Exp Ther 1997;283:1201-6
Seemuller $U$, Eulitz M, Fritz $H$, Strobl A. Structure of the elastase-cathepsin $G$ inhibitor of the leech Hirudo medicinalis. Hoppe Seylers Z Physiol Chem 1980;361:1841-6

Shin H-H, Kim S-G, Lee M-H, Suh J-H, Kwon BS, Choi H-S. Soluble glucocorticoid-induced TNF receptor (sGITR) induces inflammation in mice. Exp Mol Med 2003;35:358-64

Shin YH, Kweon OK, Fang MZ, Kim MY, Kwak HI, Son JW, Kim JH, Bae MO, Kim KY, choi SJ, Jung KH, Cho MH. Effects of guamerin, urinary trypsin inhibitor (UTI), and combined therapy of guamerin and UTI on cerulein-induced acute pancreatitis rat model. Asian Pacific $\mathrm{J}$ of Pharmacology 2000;14:21-25

Song M, Zaninovic V, Kim D, Gukovsky I, Gukovskaya A, Kang K, Pandol S. Amelioration of rat cerulein pancreatitis by guamerin-derived peptide, a novel elastase inhibitor. Pancreas 1999;18:231-9

Tonai $\mathrm{T}$, Shiba $\mathrm{K}$, Taketani $\mathrm{Y}$, Ohmoto $\mathrm{Y}$, Murata $\mathrm{K}$, Muraguchi M, Ohsaki H, Takeda E, Nishisho T. A neutrophil elastase inhibitor (ONO-5046) reduces neurologic damage after spinal cord injury in rats. J Neurochem 2001;78:1064-72

Tremblay GM, Janelle MF, Bourbonnais Y. Tremblay GM, Janelle MF, Bourbonnais $\mathrm{Y}$, Anti-inflammatory activity of neutrophil elastase inhibitors. Curr Opin Investig Drugs. 2003 May;4(5):556-65

Ueno M, Moriyama $Y$, Toda R, Yotsumoto G, Yamamoto $H$, Fukumoto Y, Sakasegawa K, Nakamura K, Sakata R. Effect of a neutrophil elastase inhibitor (ONO-5046 Na) on ischemia/reperfusion injury using the left-sided heterotopic canine heart transplantation model. J Heart Lung Transplant 2001;20:889-96

Waugh JM, Li-Hawkins J, Yuksel E, Cifra PN, Amabile PG, Hilfiker PR, Geske RS, Kuo MD, Thomas JW, Dake MD, Woo SL. Therapeutic elastase inhibition by alpha-1-antitrypsin gene transfer limits neointima formation in normal rabbits. J Vasc Interv Radiol 2001;12:1203-9

Wright CD, Kennedy JA, Zitnik RJ, Kashem MA. Inhibition of murine neutrophil serine proteinases by human and murine secretory leukocyte protease inhibitor. Biochem Biophys Res Commun 1999;254:614-7

Zaidi SHE, You X-M, Ciura S, O'Blenes S, Husain M, Rabinovitch M. Suppressed smooth muscle proliferation and inflammatory cell invasion after arterial injury in elafinoverexpressing mice. J Clin Invest 2000;105:1687-95 